\title{
Pink Esthetics: A Study on Significant Gingival Parameters
}

\author{
Abhilasha S Patil ${ }^{1}$, Venugopal Ranganath ${ }^{2}$, Sujata A Yerawadekar ${ }^{3}$, Chitragar Naresh Kumar $^{4}$, Gargi S Sarode ${ }^{5}$
}

\begin{abstract}
Aim: The aim of the study was to quantify the specific spatial displacement of gingival zenith (GZ) and determine a representative value for the interdental papilla height as a percentage ratio of clinical crown length $(\mathrm{CL})$, as measured from $\mathrm{GZ}$ in the maxillary anterior dentition.

Materials and methods: A total of 100 subjects and 1,200 interdental papillae were included. Eighty percent of the population presented with the gingival margin of lateral incisor (LI) teeth positioned coronally to the GZ of the ipsilateral canine (C) and central incisor (CI).

Results: No significant difference was found between mesial and distal papilla proportion (DPP) of maxillary incisor groups. In the C group, numerical values showed higher DPP.

Conclusion: The data achieved provide the ideal numerical values for prosthetic, restorative, periodontal, implant, postorthodontic, and esthetic treatment outcomes.

Clinical significance: The study describes the importance of quantifying the ideal numerical values for prosthetic, restorative, periodontal, implant, postorthodontic, and esthetic treatment outcomes. The readers should understand to quantify the specific spatial displacement of $\mathrm{GZ}$ and determine a representative value for the interdental papilla height as a percentage ratio of clinical $\mathrm{CL}$, as measured from $\mathrm{GZ}$ in the maxillary anterior dentition.
\end{abstract}

Keywords: Dental esthetics, Gingival zenith, Interdental papilla, Maxillary anterior, Surgery, Tooth anatomy.

The Journal of Contemporary Dental Practice (2020): 10.5005/jp-journals-10024-2739

\section{INTRODUCTION}

Smile esthetics play an important role in the perception of an individual's personality. ${ }^{1}$ The perception of facial beauty is multifactorial. Esthetics is the study that assesses and comprehends beauty, proportions, and symmetry. ${ }^{2}$ It is a fusion of art and science, and all the variables considered are interdependent and interrelated, hence it is difficult to define the ideal smile. ${ }^{3}$

There has been great advancement over the years in the field of esthetic dentistry to establish a balance in ideals of beauty with optimal health and function. ${ }^{4}$ Smile analysis involves evaluating the teeth, lip framework, and gingival scaffold, i.e., the ideal fusion of pink and white esthetics. The abnormalities in the symmetry and contour disturb the look of the natural and prosthetic restored dentition. $^{5}$

Gingival zenith (GZ) is outlined as the most apical point of gingival marginal scallop. It has a precise spatial orientation in the apicocoronal and mesiodistal directions. Mesiodistally it is located just distal to the long axis of Cls and Cs and is concurrent with the long axis of Lls. Apicocoronally zenith on Cls and Cs is at the same height and on the LIs is slightly coronal. The visibility of interdental papilla results in positive architecture esthetics while smiling. ${ }^{6,7}$

The harmony between white esthetics and pink esthetics is enhanced by correct spatial positioning of zenith, which in turn influences the emergence pattern, and axial placement of teeth. This modifies the line angle locus of long axis of crown emergence from gingiva adding equilibrium to entire soft tissue system. ${ }^{8}$ Gingival bioform is the different scallop morphologies of the marginal and interdental gingiva. There is a difference in the clinical appearance of the marginal gingiva and tooth types in different individuals. Apart from genetic predisposition, morphologic characteristics of the periodontium is influenced by a variety of factors such as size, shape, and position of tooth and physiologic processes like growth, aging, etc. Gingival biotype is affected by gingival thickness and crown
${ }^{1}$ Consulting Periodontist, Pune, Maharashtra, India

${ }^{2}$ Department of Periodontology, AECS Maaruti College of Dental Sciences and Research Center, Bengaluru, Karnataka, India

${ }^{3}$ Department of Orthodontics and Dentofacial Orthopedics, Dr DY Patil Dental College and Hospital, Dr DY Patil Vidyapeeth, Pune, Maharashtra, India

${ }^{4}$ Department of Periodontology, Vishnu Dental College, Bhimavaram, Andhra Pradesh, India

${ }^{5}$ Department of Oral Pathology and Microbiology, Dr DY Patil Dental College and Hospital, Dr DY Patil Vidyapeeth, Pune, Maharashtra, India Corresponding Author: Gargi S Sarode, Department of Oral Pathology and Microbiology, Dr DY Patil Dental College and Hospital, Dr DY Patil Vidyapeeth, Pune, Maharashtra, India, Phone: +91 9823871462, e-mail: gargi14@gmail.com

How to cite this article: Patil AS, Ranganath V, Yerawadekar SA, et al. Pink Esthetics: A Study on Significant Gingival Parameters. J Contemp Dent Pract 2020;21(2):207-210.

Source of support: Nil

Conflict of interest: None

width (CW); and crown length (CL), papilla height, and gingival width determine the gingival bioform which includes the GZ.

Different studies were also done in a variety of ethnic groups to evaluate the influence of white esthetics on pink esthetics.

AlQahtani et al. evaluated the smile line, gingival angle, and tooth shape among a subpopulation of the Saudi Arabia and their connection with gingival biotype. ${ }^{9}$ They concluded statistically significant relationship between thick gingival biotype, the square tooth, and high smile line. The high gingival angle was allied with thin gingival biotype. In all, 56.8\% demonstrated tapering tooth morphology, $53 \%$ showed thick gingival biotype, while $57.5 \%$ had average smile line.

(c) The Author(s). 2020 Open Access This article is distributed under the terms of the Creative Commons Attribution 4.0 International License (https://creativecommons. org/licenses/by-nc/4.0/), which permits unrestricted use, distribution, and non-commercial reproduction in any medium, provided you give appropriate credit to the original author(s) and the source, provide a link to the Creative Commons license, and indicate if changes were made. The Creative Commons Public Domain Dedication waiver (http://creativecommons.org/publicdomain/zero/1.0/) applies to the data made available in this article, unless otherwise stated. 
Barakat studied Syrian population for determining the predominance of gingival biotypes. ${ }^{10}$ In all, 58.4\% people showed thick gingival biotype, $41.6 \%$ had thin gingival biotype, while $99.5 \%$ of them had triangular tooth shape.

Lee determined the facial gingival profiles of teeth with a healthy periodontium in an Asian population. ${ }^{11} \mathrm{~A}$ high percentage of anterior teeth had thin marginal gingiva.

Rathee evaluated the prevalence of various gingival biotypes and corroborated gingival thickness and gingival biotypes across tooth type, site, and gender in Young Dentate North Indian Population. ${ }^{12}$ In all, 70 to $73 \%$ of $\mathrm{Cl}$ showed tendency toward thin biotype variant compared with only $23-28 \%$ with thick biotype variant.

Shah conducted a study in a South Indian population and stated that thin biotype was prevalent in $43.25 \%$, while thick gingival biotype was seen in $56.75 \% .^{13}$

The above studies surveyed a variety of population and different ethnic groups. Thus, ethnic differences impact the distribution of gingival biotypes and tooth morphology. These factors can determine the location of GZs.

There is a lack of universal guidelines along with the standardization and communication to achieve consistent outcomes of the esthetic treatment plan. Hence, there is a need to establish a mathematical quantification of certain esthetic components that satisfies both the patients and clinicians. ${ }^{14}$

Not many studies have been conducted to calculate GZ and the interdental papilla height parameters in the West Indian population. Hence the purpose of this study was to quantify the specific spatial displacement of GZ and to define a representative value for interdental papillary height as a percentage ratio of clinical $\mathrm{CL}$ as determined from $\mathrm{GZ}$.

\section{Materials and Methods}

A sample size of total 100 adult subjects (42 males and 58 females) between the age-group of 20-23 years with healthy periodontium was included in the study. Sample size computation was done using the expected prevalence of coincident $G Z$ with the long axis of tooth as $40.66 \%$. A sample size of 100 had a precision of 0.1 at a confidence interval of $95 \%$.

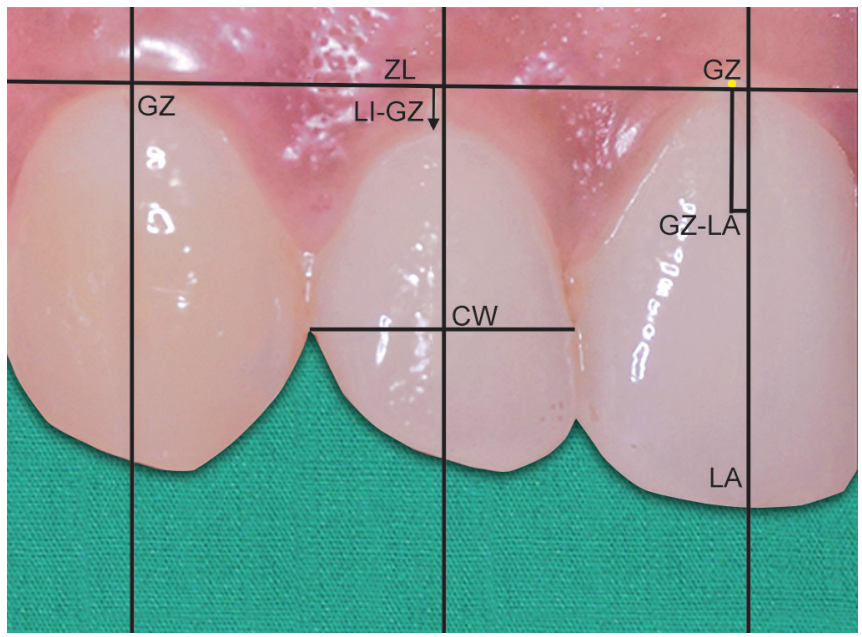

Fig. 1: Measurements performed in morphometric analysis. Gingival zenith is the most apical point of gingival zenith. The GZ-long axis distance is defined as the discrepancy between the $G Z$ and the long axis of the tooth, lateral incisor-GZ distance is defined as the vertical discrepancy between the zenith line and the zenith of the ipsilateral $\mathrm{LI}$
The study was carried out in accord with the Helsinki declaration of 1975, as revised in $2000 .{ }^{15}$ The protocol for all procedures was approved by the Institutional Review Board for Ethical Clearance of AECS Maaruti College of Dental Sciences and Research Centre Bengaluru. Subjects were informed prior and a valid informed consent was taken.

Inclusion criteria was patients who were older than 20 years, absence of bleeding on probing, suppuration, recession (REC), probing depth (PD) $<3 \mathrm{~mm}$, no loss of interdental papillae, crowding, spacing, incisal alteration, and consistency firm and resilient.

Exclusion criteria was diseases/conditions and medications affecting gingival status, gingival alterations, attachment loss, history of periodontal, orthodontic, restorative treatment, and trauma and occlusal wear of more than $1 \mathrm{~mm}$ into dentin.

\section{Clinical Data}

Probing depth, REC, and probing attachment level were measured using UNC 15 probe (HU-FRIEDY).

\section{Impression Technique}

A maxillary stock tray of an appropriate size was selected. Maxillary impression was taken using additional silicone material (GC Flexceed Putty). The impression was poured using type IV dental stone (Gyprock, India).

\section{Morphometric Analysis}

Reference lines were marked for morphometric analysis. The measurements were taken bilaterally in the $\mathrm{C}$, $\mathrm{LI}$, and $\mathrm{Cl}$ teeth using a digital vernier caliper (Aerospace Digimatic Vernier Caliper). The CW was marked at maximum CW, and long axis-clinical crown length $(\mathrm{CL})$ was marked as $(\mathrm{LA})$ which bisected the $\mathrm{CW}$. The $\mathrm{GZ}$ was the most apical point of gingival marginal scallop. Zenith line (ZL) was the horizontal line connecting gingival zenith (GZ) from the ipsilateral canine $(\mathrm{C})$ and central incisor $(\mathrm{Cl})$ teeth. The GZ-LA and $\mathrm{LI}-\mathrm{GZ}$ lines were drawn (Fig. 1). Papillary height measurements were determined from the level of the GZ to the tip of the mesial papilla (MPH) and the distal papilla (DPH) for the $\mathrm{Cl}$, LI, and the $\mathrm{C}$ (Fig. 2). Each papilla height $(\mathrm{PH})$ measurement was segmented by the clinical $C L L A$, and a percentage ratio was calculated. The MPH proportions (MPPs) and DPPs were analyzed individually using the formula MPP $=\mathrm{MPH} / \mathrm{CL} \times$ $100 \%$, and DPP $=\mathrm{DPH} / \mathrm{CL} \times 100 \%$. Measurements were documented to the nearest 1/100th $\mathrm{mm}$. Duplicate measurements were achieved for every tooth and averaged.

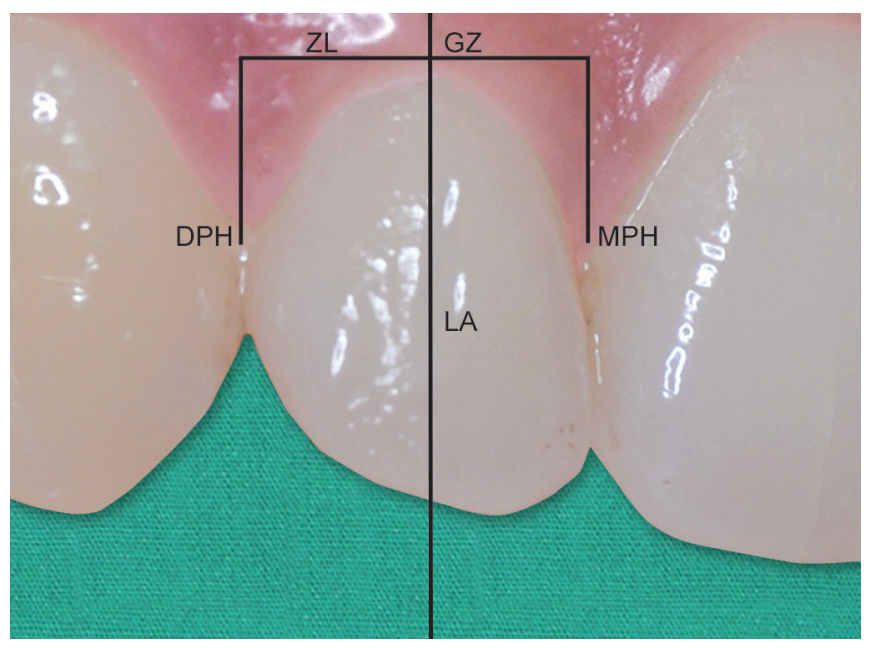

Fig. 2: Measurement performed in morphometric analysis. Each papilla height $(\mathrm{PH})$ measurement was divided by the clinical crown length and a percentage ratio was calculated 
Pink Esthetics

Table 1: Values showing the distal displacement of the gingival zenith in relation to the long axis of the tooth

\begin{tabular}{lllllll}
\hline Measurement & $R C$ & $R L I$ & $R C I$ & $L C I$ & $L L I$ & $L C$ \\
\hline Mean $\pm \mathrm{SD}(\mathrm{mm})$ & $0.15 \pm 0.30$ & $0.36 \pm 0.42$ & $0.84 \pm 0.38$ & $0.87 \pm 0.49$ & $0.43 \pm 0.40$ & $0.06 \pm 0.24$ \\
Range-min/max $(\mathrm{mm})$ & $0.0 / 0.9$ & $0.0 / 1.3$ & $0.0 / 1.6$ & $0.0 / 1.75$ & $0.0 / 1.40$ & $0.0 / 1.2$ \\
\hline
\end{tabular}

$\mathrm{RC}$, right canine; $\mathrm{RLI}$, right lateral incisor; $\mathrm{RCl}$, right central incisor; $\mathrm{LCl}$, left central incisor; $\mathrm{LLI}$, left lateral incisor; $\mathrm{LC}$, left canine; Min/max, minimum/ maximum values; $\mathrm{SD}$, standard deviation

Table 2: Values showing the prevalence percentage of the coincidence of the position of the gingival zenith with the long axis of the tooth

\begin{tabular}{lrcccccc}
\hline & $R C$ & $L C$ & $R L I$ & $L L I$ & $R C I$ & $L C I$ & Total \\
\hline Coincide (\%) & 88 & 96 & 22 & 28 & 4 & 8 & 41 \\
Mean (\%) & 92 & & 25 & & 6 & & \\
$p<0.05$ & & & & & & & \\
Diverge (\%) & 12 & 4 & 78 & 72 & 96 & 92 & 59 \\
Mean (\%) & 8 & & 75 & & 94 & &
\end{tabular}

$p<0.05$

$\mathrm{RC}$, right canine; $\mathrm{RLI}$, right lateral incisor; $\mathrm{RCl}$, right central incisor; $\mathrm{LCl}$, left central incisor; LLI, left lateral incisor; LC, left canine

Table 3:Values showing the coronal displacement of the gingival zenith of the maxillary lateral incisor

\begin{tabular}{llll}
\hline & $R L I$ & $L L I$ & Total \\
\hline Mean \pm SD & $0.80 \pm 0.66$ & $0.85 \pm 0.68$ & $0.85 \pm 0.68$ \\
Range $(\mathrm{mm})$ & $0.40-1.5$ & $0.44-1.8$ & $0.44-1.8$ \\
$p$ value & 0.40 (NS) & & \\
\hline
\end{tabular}

$\mathrm{RLI}$, right lateral incisor; LLI, left lateral incisor; SD, standard deviation

\section{Results}

All results are stated as mean \pm standard deviation (SD). Intermeasurement disparities were studied by paired $t$ test for continuous variables and the $\chi^{2}$ test for percentages. $p<0.05$ was used to affirm statistical significance (Tables 1 and 2).

In Cs, the long axis of crown is coincident with zenith in $88 \%$ of right and $96 \%$ of left. In the right $C$, a distal displacement of $0.15 \pm$ $0.30 \mathrm{~mm}$ was seen. Zenith was not coincident in $12 \%$, with distal displacement minimum of $0.0 \mathrm{~mm}$ and maximum of $0.9 \mathrm{~mm}$. In the left $C$ a distal displacement of $0.06 \pm 0.24 \mathrm{~mm}$ was seen. Zenith was not coincident in $4 \%$ with distal displacement minimum of $0.0 \mathrm{~mm}$ and maximum of $1.2 \mathrm{~mm}$. Due to statistical insignificance (paired $t$ test $p=0.25$ ), it was concluded that right and left $C$ demonstrated contralateral symmetry.

In LIs, the long axis of crown is coincident with zenith in $22 \%$ of right and $28 \%$ of left. In the right Lls, a distal displacement of $0.36 \pm$ $0.42 \mathrm{~mm}$ was seen. Zenith was not coincident in $78 \%$, with distal displacement minimum of $0.0 \mathrm{~mm}$ and maximum of $1.3 \mathrm{~mm}$. In the left Lls, a distal displacement of $0.43 \pm 0.40 \mathrm{~mm}$ was seen. Zenith was not coincident in $72 \%$ with distal displacement minimum of $0.0 \mathrm{~mm}$ and maximum of $1.4 \mathrm{~mm}$.

In Cls, the long axis of crown is coincident with zenith in $4 \%$ of right and $8 \%$ of left. In the right $\mathrm{Cls}$, a distal displacement of $0.84 \pm$ $0.38 \mathrm{~mm}$ was seen. Zenith was not coincident in $96 \%$, with distal displacement minimum of $0.0 \mathrm{~mm}$ and maximum of $1.6 \mathrm{~mm}$. In the left Cls, a distal displacement of $0.87 \pm 0.49 \mathrm{~mm}$ was seen. Zenith was not coincident in $92 \%$ with distal displacement minimum of $0.0 \mathrm{~mm}$ and maximum of $1.75 \mathrm{~mm}$.

It was inferred that mesial displacement of GZ was not seen in any tooth groups of the maxillary anterior region.
Contralateral symmetry was observed for distal displacement of all teeth group. Distal displacement was maximum in Cls followed by Lls and Cs ( $\chi^{2}$ test $\left.p<0.05\right)$. Maximum of population showed gingival margin positioned coronal to zeniths of ipsilateral $\mathrm{C}$ and $\mathrm{Cl}$ teeth.

\section{Coronal Displacement of the LI Zenith (Table 3)}

A majority of the cases (80\%) presented with the gingival margin of $\mathrm{LI}$ teeth positioned coronally to the zeniths of the ipsilateral $\mathrm{C}$ and $\mathrm{Cl}$ teeth. Such coronal displacement amounted to $0.80 \pm 0.66 \mathrm{~mm}$ (range, $0.40-1.5 \mathrm{~mm}$ ) for right $\mathrm{LI}$ and $0.85 \pm 0.68 \mathrm{~mm}$ (range, 0.44-1.8 $\mathrm{mm}$ ) for left LI. These differences were statistically insignificant (paired $t$ test; $p=0.40$ ). Of the cases studied, $17 \%$ presented with the gingival margin of $\mathrm{LI}$ teeth situated at the same level of the zeniths of the ipsilateral $\mathrm{C}$ and $\mathrm{Cl}$ teeth. In $3 \%$ of the cases, the LI was sited apically to the neighboring teeth.

\section{Papillary Proportions (Table 4)}

The MPPs for the $\mathrm{Cl}$, $\mathrm{LI}$, and $\mathrm{C}$ were $38,34.5$, and $40 \%$, respectively. The DPPs of the $\mathrm{Cl}, \mathrm{LI}$, and $\mathrm{C}$ were $38.5,36$, and $40.5 \%$, respectively. No significant difference was observed between MPP and DPP of maxillary incisor groups. In the $C$ group, the numerical values showed higher DPP.

\section{Discussion}

The results of the current study concluded that distal movement of GZ was not a universal feature. The most anterior tooth showed greater distal displacement of GZ. This was in agreement with the previous study done by Mattos and Santana, which stated that the GZ was distally displaced between 0.06 and $0.96 \mathrm{~mm}$ in 12, 70, and $96 \%$ of the C, $\mathrm{LI}$, and $\mathrm{Cl}$ teeth, respectively. ${ }^{16}$ Seventy percent of the population presented with the GZ of LI teeth placed coronally to the GZ. Chu revealed a GZ had a mean value of $1 \mathrm{~mm}$ distal from the vertical bisected midline for the $\mathrm{Cl}$ tooth group. ${ }^{17}$ The LIs displayed a mean of $0.4 \mathrm{~mm}$. The $C$ tooth group revealed no deviations in the $G Z$ from the vertical bisected midline. The $G Z$ of the LIs related to the adjacent $\mathrm{Cl}$ and $\mathrm{C}$ teeth were more coronal by $1 \mathrm{~mm}$ approximately. Stein and Kay proposed that the zenith is distal to the long axis of $\mathrm{Cl}$ and $\mathrm{LI}$ teeth. ${ }^{18,19}$ Magne and Belser and Morr proposed that the zenith is distal to the long axis of $\mathrm{Cl}, \mathrm{LI}$, and C teeth. ${ }^{20,21}$ Cho et al. concluded that the interradicular distance and the distance between the contact point and the alveolar crest have separate and joint effects on the presence or absence of interdental papilla. ${ }^{22}$ Tarnow et al. examined the distance from the base of the contact area to the crest of bone in 288 sites and determined that at 5,6 , and $7 \mathrm{~mm}$ the papilla was present 98,56 , and $27 \%$ of the time, respectively. ${ }^{23}$ Kois measured mesial sites at the maxillary right $\mathrm{Cl}$ in 100 healthy patients and he reported a interproximal depth range of 3-4.5 mm. ${ }^{24}$ In the present study, the average MPP for the $\mathrm{Cl}$, LI, and C were $38,34.5$, and $40 \%$, respectively. The DPPs of the $\mathrm{Cl}, \mathrm{LI}$, and C were $38.5,36$, and $40.5 \%$, respectively. These results are consistent with the study done by Chu and Patil who reported insignificant differences between MPP and DPP for maxillary incisors and a distal trend for the Cs. ${ }^{14,25}$ 
Table 4: Values showing the percentage ratio of papilla height to crown length sorted by tooth position and divided into mesial and distal groups

\begin{tabular}{llllll}
\hline Tooth & Sample & & Mean \pm SD & Min & Max \\
\hline Right C & 100 & MPP & $40 \pm 6$ & 32 & 50 \\
Right C & 100 & DPP & $40 \pm 6$ & 33 & 50 \\
Right LI & 100 & MPP & $34 \pm 7$ & 24 & 47 \\
Right LI & 100 & DPP & $34 \pm 7$ & 25 & 47 \\
Right Cl & 100 & MPP & $38 \pm 5$ & 32 & 46 \\
Right Cl & 100 & DPP & $38 \pm 5$ & 33 & 46 \\
Left Cl & 100 & MPP & $38 \pm 5$ & 33 & 46 \\
Left Cl & 100 & DPP & $39 \pm 4$ & 32 & 46 \\
Left LI & 100 & MPP & $35 \pm 7$ & 26 & 47 \\
Left LI & 100 & DPP & $37 \pm 6$ & 26 & 47 \\
Left C & 100 & MPP & $40 \pm 5$ & 34 & 50 \\
Left C & 100 & DPP & $41 \pm 5$ & 37 & 50 \\
\hline RC,
\end{tabular}

$\mathrm{RC}$, right canine; $\mathrm{RLI}$, right lateral incisor; $\mathrm{RCl}$, right central incisor; $\mathrm{LCl}$, left central incisor; LLI, left lateral incisor; LC, left canine; MPP, mesial papilla proportion; DPP, distal papilla proportion; SD, standard deviation

\section{ConcLusion}

The present study provided direct quantitative measurements and qualitative descriptive statistics of the relative position of the $G Z$ in the maxillary anterior sextant and the interdental papilla location. The positioning of the gingival margin during periodontal, orthodontic, restorative, and orthognathic surgical therapy can be determined using this data. The knowledge and application of some numeric guidelines offer significant help during complex situations. These numericals used in conjunction with other objective and subjective parameters aid the clinician in placing the gingival contours during surgery. Soft tissue dental esthetics management and success are always based on a careful planning of the operation. Incorrect placement of gingival margins not only results in pink esthetic failure but also affects the success of restorative procedure done. Hence, a proper interdisciplinary approach is necessary for the overall esthetic success.

\section{Presentation}

This original study won the first prize as a paper presentation titled "A quantitative spatial displacement of GZ and the mathematical expression of the interdental papilla location in the maxillary anterior dentition" at the 41st Karnataka State Dental Conference, Madikeri, Coorg, Karnataka, India, on November 22, 2014.

\section{Pink Esthetics}

Evaluation of $\mathrm{GZ}$ and the mathematical expression of interdental papilla location in the maxillary esthetic zone.

\section{References}

1. Malkinson S, Waldrop CT, Gunsolley CJ, et al. The effect of esthetic crown lengthening on perceptions of a patient's attractiveness, friendliness, trustworthiness, intelligence, and self-confidence. J Periodontol 2013;84(8):1126-1133. DOI: 10.1902/jop.2012.120403.

2. Naini FB, Moss JP, Gill DS. The enigma of facial beauty: esthetics, proportions, deformity, and controversy. Am J Orthod Dentofacial Orthop 2006;130(3):277-282. DOI: 10.1016/j.ajodo.2005.09.027.

3. Ahmad I. Anterior dental esthetics: historical perspective. Br Dent J 2005;198(12):737-742. DOI: 10.1038/sj.bdj.4812411.
4. Hochman NM, Chu JS, Tarnow PD. Maxillary anterior papilla display during smiling: a clinical study of the interdental smile line. Int J Periodontics Restorative Dent 2012;32(4):375-383.

5. Garber DA, Salama MA. The esthetic smile: diagnosis and treatment. Periodontol 2000 1996;11:18-28. DOI: 10.1111/j.1600-0757.1996. tb00179.x.

6. Takei $\mathrm{H}$, Yamada $\mathrm{H}, \mathrm{Hau}$ T. Maxillary anterior esthetics. Preservation of the interdental papilla. Dent Clin North Am 1989;33(2):263-273.

7. Takel HH. The interdental space. Dent Clin North Am 1980;24(2): 169-176.

8. Goodlin R, . Gingival esthetics: a critical factor in smile design. Oral Health and Dental Practice Management [serial online]. April 2003. Available at: http://www. oralhealthjournal.com/issues/ISarticle. asp?id=97035\&story_id $=155216115410 \&$ issue $=04012$ 003\&PC $=$. Accessed November 24, 2007.

9. AlQahtani NA, Haralur BS, AIMaqbol M, et al. Distribution of smile line, gingival angle and tooth shape among the Saudi Arabian subpopulation and their association with gingival biotype. J Int Soc Prev Community Dent 2016;6(Suppl 1):S53-S58. DOI: 10.4103/22310762.181168 .

10. Barakat $H$, Dayoub S. Prevalence of gingival biotype in a Syrian population and its relation to tooth shapes: a crosssectional study. J Biomed Sci Eng 2016;9(3):141-146. DOI: 10.4236/ jbise.2016.93010.

11. Lee $W Z$, Ong MM, Yeo AB. Gingival profiles in a select Asian cohort: a pilot study. J Investig Clin Dent 2018;9(1).

12. Rathee M, Rao LP, Bhoria M. Prevalence of gingival biotypes among young dentate North Indian population: a biometric approach. Int J Clin Pediatr Dent 2016;9(2):104-108. DOI: 10.5005/ jp-journals-10005-1343.

13. Shah R, Sowmya NK, Thomas R, et al. Periodontal biotype: basics and clinical considerations. J Interdiscip Dent 2016;6:44-49.

14. Chu SJ, Tarnow DP, Tan JH, et al. Papilla proportions in the maxillary anterior dentition. Int J Periodontics Restorative Dent 2009;29(4): 385-393.

15. Crigger BJ. Declaration of Helsinki revised. IRB 2000;22(5):10-11.

16. Mattos C, Santana R. A quantitative evaluation of the spatial displacement of the gingival zenith in the maxillary anterior dentition. J Periodontol 2008;79(10):1880-1885. DOI: 10.1902/ jop.2008.080053.

17. Chu S, Tan J, Steppart C, et al. Gingival zenith positions and levels of the maxillary anterior dentition. J Esthet Restor Dent 2009;21(2): 113-120. DOI: 10.1111/j.1708-8240.2009.00242.x.

18. Stein RS, Kuwata M. A dentist and a dental technologist analyze current ceramo-metal procedures. Dent Clin North Am 1977;21(4):729-749.

19. Kay HB. Esthetic considerations in the definitive periodontal prosthetic management of the maxillary anterior segment. Int J Periodontics Restorative Dent 1982;2(3):44-59.

20. Magne $\mathrm{P}$, Belser U. Bonded Porcelain Restorations in the Anterior Dentition: A Biomimetic Approach. Chicago: Quintessence Publishing; 2002. pp. 57-98.

21. Morr T. Understanding the esthetic evaluation for success. J Calif Dent Assoc 2004;32(2):153-160.

22. Cho HS, Jang HS, Kim DK, et al. The effects of interproximal distance between roots on the existence of interdental papillae according to the distance from the contact point to the alveolar crest. J Periodontol 2006;77(10):1651-1657. DOI: 10.1902/jop.2006.060023.

23. Tarnow DP, Magner AW, Fletcher P. The effect of the distance from the contact point to the crest of bone on the presence or absence of the interproximal dental papilla. J Periodontol 1992;63(12):995-996. DOI: 10.1902/jop.1992.63.12.995.

24. Kois JC. Altering gingival levels: the restorative connection. Part I: biologic variables. J Esthet Dent 1994;6(1):3-7. DOI: 10.1111/j.17088240.1994.tb00825.x.

25. Patil VA, Desai MH. Assessment of gingival contours for esthetic diagnosis and treatment: a clinical study. Indian J Dent Res 2013;24(3):394-395. DOI: 10.4103/0970-9290.118005. 